\title{
The Importance of the Organizational Identification in Forming Organizational Perception
}

\author{
HAMZAGIĆ Enes ${ }^{5}$
}

\begin{abstract}
There has been a great number of researches concerning the organizational identification in the last two decades. Unfortunately, little work has been done on how the organizational identification is formed. We made a literature review, which was concerning the process on which the organizational identification is being formed. This work consolidates the literature about the role of the organizational culture in process of identification. Five steps were identified in organizational identification formation (1) strong organizational culture, (2) effective management, (3) good communication channels, (4) formation of psychological contract, (5) common organizational value sharing, (6) decision making premises.
\end{abstract}

Keywords: organizational identification; organizational culture; decision making

JEL: D20

UDC: 005.32

COBISS.SR-ID 265398540

\section{Introduction}

Identification is an ongoing process, where individuals tend to link themselves to a certain social element. When employees highly identify themselves with organization, they accept values and norms, held by certain organization. Hogg and Terry (2000) emphasis the importance of organization as social category, and the employees who identify with their organization have self-images that are reconstituted in the organization's image and values (Cheney, 1983). It is empirically proven that culture is influencing the way we perceive and conceives, still more research needs to be done concerning the way organization perceives.

For the common perception to be achieved, employees need to embed the organization's value system in their self-definition. The way on which organizational identification (OI) is formed is still unclear. The questions which arise are the ones concerning the actual transfer and embeddedness of the values from organization towards their employees. The content and the type of organizational identification may differ, but the researches emphasis two ways on which OI is being transferred, the importance of communication and the importance of managers. OI is often seen as a construct of social identification (Bergami and Bagozzi, 2000).

Riketta (2005) classified present literature on OI into three study approaches, namely cognitive, affective, and sociological identification. Cognitive behavior is reflected in employee's intent to make decisions by considering the consequences of the actions towards the organization. Barker and Tompkin (1994) stated that when employees in the organization

${ }^{5}$ IAE Nice Graduate School of Management, France. 
accept the organization values and goals, that the decision-making will be organization's value and goal based. This may lower costs concerning the wrong decision making and special trainings concerning the value transfer. Organizational identification is influenced by organizational distinctiveness, organizational prestige, and external and internal competitions as one of the main factors (Mael and Ashforth, 1992).

Our thoughts, which are following this paper, are based on Dutton et al., (1994) view that when higher the level of identification with the organization is, the employee will act and think from an organization's perspective. We will do literature review on process of identification with organizations and try to identify the ways in which OI is being formed.

\section{Organizational identification}

There have been great shifts in global markets in recent years. The external factors have influenced the employees to change jobs frequently. OI, as theory of social identity, tried to explain the employee's process of self-concept and its identification with the organization.

Transfer of organizational identity is a process in which organization's values are being accepted and practiced by its employees. Freud (1922) described identification as "an emotional tie with another person". This idea was later used for organizational identification (Patchen, 1970).

It is crucial for employees to identify themselves with the organization. The stronger the identification is, the faster and more efficient achievements of organization's goals will be.

Linking to certain elements of "social scene" will ease the implementation, policies, and acts won't be necessary. Employee's attitudes, behavior and motivation has often been linked to OI.

Different types of the organizational commitment may be found in the organization, such as normative commitment (Marsh and Mannari, 1977), affective commitment (Meyer \& Allen, 1991) and continuance commitment (Hrebiniak and Alutto, 1972). Theoretically, researches differentiate the concepts of commitment and identification. Commitment is more material based (Tyler and Blader, 2000), which depends on the exchange between the employees and the organization. The identification is deeper concept which evolves the sharing of mutual values and norms. The organizational identification is substantially related only to affective type of commitment (Gautam, 2004; Mael and Tetrick, 1992). One of the key criteria for identification is employee's view of organization as distinctive and prestigious (Carmeli, Gilat, \& Weisberg, 2006).

The strength of organizational identification is correlated with organizational image and prestige (Carmeli, 2005; Dukerich et al., 2002). Furthermore, employees' attitudes would be affected by aspects of a firm's performance (Schneider et al., 2003). Having higher organizational identification does not de facto mean that the performance will be better. The study of Riketta (2005) shows the weak to the moderate relationship between identification and in-role performance and extra-role behavior.

\section{Formation of OI}

There are two theories concerning the formation of OI. Cheney and Christensen (2001) stated that, since managers can use internal communication channels of the organization, that may enable them to influence the official claims of the organization. While the second theory states that OI is perceived by communication, as a kind of interpersonal interaction, communication is affected by cultural background to a large degree (Cheney, 1983). 


\section{Information Theory}

Information theory is affecting OI in senses of receiving process and transmitting the information, as one main aspect of OI formation. Information, are in general, very important for OI formation, since employees strive for information, in order to feel as important members of organization. Information is one of the main pillars in forming the organizational identification. If a group passes on with conviction elements of a way of perceiving, thinking, and feeling, we can assume that that group has had enough stability and has shared enough common experience to have developed a culture (Schein, 1984). Information with different content may differently impact OI. As Cheney's (1983) analysis showed, there are two kinds of information: visual-information and persuasive information.

\section{Leadership}

Leaders must create organizational culture. Whether it will be strong organizational culture or not has its pros and cons. The leaders should create organizational culture which will embrace the creativeness and open minded, even within the employees which have high OI.

They are responsible for defining organization's norms and values. Managing the culture, in the way of establishing the system of norms and certain shared system of behavior. Each employee is bringing its own cultural heritage inside the organization, effective culture managements allows the "melting pot" and allows the embeddedness of organizational culture.

Beside the organizational culture, strong occupational culture may be one of the determinants of achieving higher level of OI. Managers have certain level of responsibility in transmitting the norms and values which are part of organizational culture. According to Schultz et al., (2000) OI provides a flexible approach for managers which could help them harmonize and resolve contradictions in a complicated and diverse organizational context.

When employee identify himself with an organization and its value system, he will represent organization, embrace corporate interests and act in organization best interest (Simon 1976; Miller, 2000).

\section{Communication}

Communication is one of the mediums used to express our thoughts. It is pillar for successful exchange of thoughts. The importance of communication between managers and employees, as key channel in order for organizational values system to be perceive, has been suggested by many researchers (Jun et al., 2010; Smidts 2001). Communication is the key for successful organizational identification. In order for OI to be achieved, the effective communication between managers and employees need to be conducted. The perceived communication climate, subdivided into three dimensions (i.e. openness, participation and supportiveness), appeared to directly affect employees' organizational identification (Bartels et al., 2006). Buchanan (1974) believed that when employees achieve affective commitment, values and goals become embedded into their role.

Table 1. Stages of forming Organizational Identification

\begin{tabular}{|ll|}
\hline $\begin{array}{l}\text { Stage 1: } \\
\text { Founder's culture }\end{array}$ & $\begin{array}{l}\text { Most cultural solutions in new groups and } \\
\text { organizations originate from the founders } \\
\text { and early leaders of those organizations } \\
\text { (Pettigrew, 1979). }\end{array}$ \\
\hline Stage 2: & $\begin{array}{l}\text { Managers are often seen as members of a } \\
\text { given group. They have, according to }\end{array}$ \\
Managers & $\begin{array}{l}\text { Schein (2015), (1) been together long } \\
\text { enough to have shared significant }\end{array}$ \\
\hline
\end{tabular}




\begin{tabular}{|c|c|}
\hline & $\begin{array}{l}\text { problems, (2) have had opportunities to } \\
\text { solve these problems and to observe the } \\
\text { effects of their solutions, (3) have taken in } \\
\text { new members. }\end{array}$ \\
\hline $\begin{array}{l}\text { Stage 3: } \\
\text { Communication }\end{array}$ & $\begin{array}{l}\text { Employees commitment appear to be in } \\
\text { direct correlation with the perception of } \\
\text { communication quality (Smidts et al., } \\
\text { 2001; Postmes et al., 2001; Cheney, 1983). }\end{array}$ \\
\hline $\begin{array}{l}\text { Stage 4: } \\
\text { Psychological contract }\end{array}$ & $\begin{array}{l}\text { Schein (1965) stated that individuals and } \\
\text { organizations interact in complex fashion. } \\
\text { Such relationship is "unfolding through } \\
\text { mutual influence and mutual bargaining to } \\
\text { establish a workable psychological } \\
\text { contract." }\end{array}$ \\
\hline $\begin{array}{l}\text { Stage 5: } \\
\text { Common organizational value sharing }\end{array}$ & $\begin{array}{l}\text { De Long and Fahey (2000) believed that } \\
\text { values and norms, held by organizational } \\
\text { members, help them develop certain sense- } \\
\text { making filters and meaning-construction } \\
\text { process. }\end{array}$ \\
\hline $\begin{array}{l}\text { Stage 6: } \\
\text { Decision making premises }\end{array}$ & $\begin{array}{l}\text { When individuals adopt the values and } \\
\text { goals of an organization, they develop } \\
\text { decision-making premises that complement } \\
\text { the value- and goal-based premises held by } \\
\text { the organization (Simon, 1976). }\end{array}$ \\
\hline
\end{tabular}

\section{Decision making premises}

Theory of organizational identification stated that when the process of transitions between organization and employee is conducted, the employee's interaction with outer environment will be in order with organization's values and believes. Simon (1948) believes that main pillar in decision making process is identification, "a person identifies with a group when, in making a decision, he evaluates the several alternatives of choice in terms of the consequences for the specified group".

The organization "initiates" this inducement process by communicating values, goals, and information (i.e., the organization's own stated "identifications") in the form of decisional premises; the member may "complete" the process by adopting or adapting the organizational premises, making decisions that are "best" for the organization, perhaps even developing a salient identification with the organization as a target. Chiney (2009) conducted research at division offices of a large industrial and high technology corporation, ranked in the top 100 of the "Fortune 500. The results of interviewing 178 employees showed that" a person identifies with a unit when, in making a decision, the person in one or more of his/her organizational roles perceives that unit's interests - AS that unit's interests - to be relevant in evaluating the alternatives of choice". Archiving such level of OI, where employees act in accordance with organization values, will presumably increase the level of good over bad decisions.

\section{Cultural determinant and $\mathrm{OI}$}

Each individual brings his cultural background. If we regard culture as onion, central of it are values. Our cultural identity is being formed through our ontogenetic development. Values formation is ongoing process, although the fundaments of it are being formed early in life.

Since official claims of the organization may be influenced by managers, which are per se representatives of their national cultures, organizational decisions are culturally determined. 
The question which arise is in what degree does national culture or organizational culture influence the decision-making process?

Hypothesis that perception is partially determined by specific, identifiable experiences made much attention in the past. The basic view of this hypothesis is that members of two different cultures will differ in their answers to perceptual tests. It is believed that motivation, emotion, experiences and culture may influence perceptual and visual perception. The differences in the perception of visual worlds could be seen in arts. Every individual has the chance to learn more about his own system of perception, we may learn more about structure of our own system simply by interacting with people coming from cultural context unlike our own. Art, as one of the systems of communication was presented for a century. Painters used pictures to present their perceptual words. Leonardo da Vinci introduced the vanishing points, and his picture The last supper was made with modified linear perspective. The last supper gave viewers experience as the walls on picture are the same as the ones in the room.

Metaphors as concept in organizational theory were developed by Mats Alvesson (2012), and they were used in research by John Hassard and Martin Parker (1993). They were seen as the source of new ideas, with generative capability. Metaphors concept was divided on firstlevel and second-level. First-level metaphor (organization as game) is developed in sub-sets metaphors, so called second-level metaphors. Second-level metaphor are generated so that culture (first-level metaphor) combined with modifier and the metaphor culture as secondlevel metaphor is generated. This concept corresponds to the view of organizations and their spiral development. Producing new metaphors is the way of how new ideas and perspectives are being born.

It is often believed that when two people are fed with data, that they will experience and record those data similarly. According to Edward Hall, people not only speak different languages, but they inhibit different sensory worlds, meaning that they do selective screening of sensory data and filters out other data.

"Hundreds of such experiences convince me that men and women often inhabit quite different visual worlds. These are differences which cannot be attributed to variations in visual acuity others, so that experience as it is perceived" (Hall, 1966).

Hall (1966) believed that by studying the art of the past, we may learn two things from it: (1) something from our own responses about the nature and organization of our own visual systems and expectations, and (2) some notion of what the perceptual world of early man may have been like.

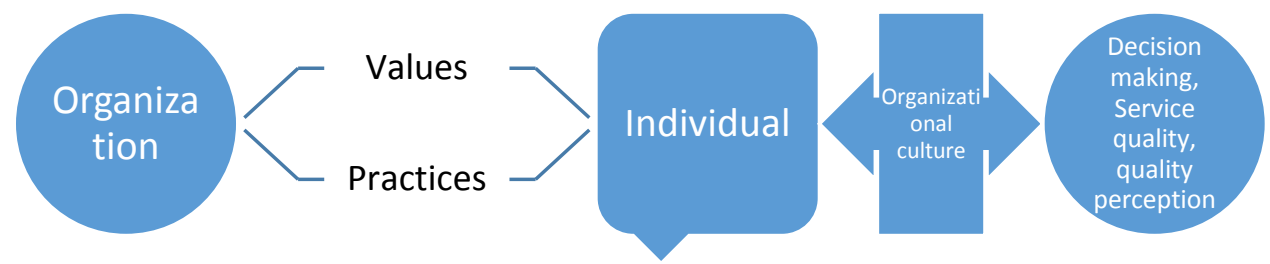

Fig. 1. Forming the organizational perception

\section{Measuring the $\mathrm{OI}$}

Measuring the cultural variables have often been a challenge. Organizations as social category are under the "touch" of culture; however, we do often simplify the way we want to measure cultures. Schein (2015) believed that culture, as such a complex system, can't be so easily measured by "small set of questions".

According to Patchen (1970) OI is composed of three interwoven factors, namely membership, royalty, and similarity. Organizational Identification Questionnaire (OIQ) was 
developed by Cheney (1983), inspired by Patchen ideas. Phinney (1991) added fourth dimensions, which was concerning the behavioral aspect of identification. Miller (2000) did the revision of OIQ and he investigated the internal dimensions of the OIQ. His results showed that only 12 , out of 25 items contribute meaningfully to the scale, for which he stated that are measuring organizational commitment, rather than organizational identification.

Gautam et al., (2004) developed revised OI questionnaire, using the original Cheney (1983) research. The revised version consisted of eight-item scale as a reliable OI measure. Edward et al., (2007) used six-item measure of OI, which measures both cognitive and affective component. These measures are composed of three subcomponents: self-categorization and labeling, sharing organizational values and goals, and a sense of organizational belonging and membership.

\section{Summary and Conclusion}

We have attempted to summarize the literature review concerning the linkage between individuals and the organizations, as most important social category.

Identification with social category will allow individuals to develop certain types of selfconceptions. OI is directly tied to the organizational culture.

Literature emphasis the importance of organizational culture, and its link with organizational identification. The stronger identification, the more efficient relation is to the organizational culture. Management is often seen as mediating factor in such relationships, which should foster the OI, especially when the identity is indistinct. Successful OI can lead to number of positive effects, such as lower training costs, harmful decision making, policies making and etc.

Still, having a higher organizational identification does not necessarily mean that the performance will be higher. The cons of OI has not been studied much.

High OI may in certain cases oppress the expression of creativity and can maybe blindfold employees about the necessity for value changing.

One of the main pillars in effective OI is organizational culture. The managers, as organizational officials, are responsible for spreading the organizational identification through information sharing with the new members. When employee identify himself with the organization, organization value system become embedded in his self definition. With "transfer" being made, organizational representatives tend to make decisions in compliance with organization. Such "an emotional tie" with the organization tends to become part of our social identity.

\section{REFERENCES}

1. Alvesson, M. (2012). Understanding organizational culture. Sage.

2. Bartels, Jos, et al., (2006). "Organizational identification during a merger: Determinants of employees' expected identification with the new organization." British Journal of Management17.S1

3. Bergami, M., Bagozzi, R.P. (2000). "Self-categorization, affective commitment and group self-esteem as distinct aspects of social identity in the organization." British Journal of Social Psychology 39.4, 555-577.

4. Buchanan, B. (1974). "Building organizational commitment: The socialization of managers in work organizations." Administrative science quarterly 533-546.

5. Carmeli, A., Gershon, G., Weisberg, J. (2006). "Perceived external prestige, organizational identification and affective commitment: A stakeholder approach." Corporate Reputation Review 9.2 (2006): 92-104. 
6. Carmeli, A. (2005). "Perceived external prestige, affective commitment, and citizenship behaviors." Organization studies26.3 (2005): 443-464.

7. Cheney, G. (1982). "Identification as process and product: A field study." Unpublished master's thesis, Purdue University, West Lafayette, IN (1982).

8. Cheney, G. (1983). "The rhetoric of identification and the study of organizational communication.” Quarterly journal of speech 69.2 (1983): 143-158.

9. Dukerich, J. M., Golden, B.R., Shortell, S.M. (2002). "Beauty is in the eye of the beholder: The impact of organizational identification, identity, and image on the cooperative behaviors of physicians.” Administrative Science Quarterly 47.3 (2002): 507-533.

10. Edwards, M. R., Peccei, R. (2007). “Organizational identification: Development and testing of a conceptually grounded measure." European journal of work and organizational psychology 16.1: 25-57.

11. Gautam, T., Van Dick, R., Wagner, U. (2004). "Organizational identification and organizational commitment: Distinct aspects of two related concepts." Asian Journal of Social Psychology 7.3: 301-315.

12. Hogg, M. A., Terry, D.I. (2000). "Social identity and self-categorization processes in organizational contexts." Academy of management review 25.1: 121-140.

13. Hrebiniak, L. G., Alutto. J.A. (1972). "Personal and role-related factors in the development of organizational commitment." Administrative science quarterly (1972): 555-573.

14. Jones, E. et al., (2004). "Organizational communication: Challenges for the new century." Journal of Communication 54.4: 722-750.

15. Jun, W. E. I., Z. H. A. N. G. Mian, Y. A. N. G. B. (2010). "Does the traditional culture affect organizational identification? An analysis of the perception channels in organizational identification of Chinese employees." Frontiers of Business Research in China 4.1 (2010): 343-361.

16. Mael, F.A., Tetrick, L.E. (1992). “Identifying organizational identification." Educational and psychological measurement 52.4 (1992): 813-824.

17. Mael, F, Ashforth, B.E. (1992). "Alumni and their alma mater: A partial test of the reformulated model of organizational identification." Journal of organizational Behavior 13.2 (1992): 103-123.

18. Marsh, R. M., Hiroshi, M. (1977). "Organizational commitment and turnover: A prediction study." Administrative Science Quarterly (1977): 57-75.

19. Meyer, J.P., Allen, N.J. (1991). "A three-component conceptualization of organizational commitment." Human resource management review 1.1 (1991): 6189.

20. Miller, V.D. et al., (2000). "Reconsidering the organizational identification questionnaire." Management communication quarterly 13.4 (2000): 626-658.

21. Parker, J. H. M. (1993). Postmodernism and organizations. Sage, 1993

22. Patchen, M. (1970). "Participation, achievement, and involvement on the job." (1970).

23. Pettigrew, A. M. (1979). "On studying organizational cultures." Administrative science quarterly 24.4 (1979): 570-581.

24. Postmes, T., Tanis, M., De Wit. (2001). "Communication and commitment in organizations: A social identity approach.” Group Processes \& Intergroup Relations 4.3 , p. 227-246.

25. Riketta, M. (2005). "Organizational identification: A meta-analysis.” Journal of vocational behavior $66.2,358-384$. 
26. Schein, E. H. (2015). "Organizational psychology then and now: Some observations." Annu. Rev. Organ. Psychol. Organ. Behav. 2.1: 1-19. APA.

27. Schneider, B., et al., (2003). "Which comes first: employee attitudes or organizational financial and market performance?” Journal of applied psychology 88.5: 836 .

28. Schultz, M., Hatch, M.J., Mogens, H. L. (2000). eds. The expressive organization: Linking identity, reputation, and the corporate brand: Linking identity, reputation, and the corporate brand. OUP Oxford.

29. Simon, H. A. (1948). Administrative behaviour: A study of the decision-making processes in administrative organisation. Macmillan Company.

30. Smidts, A., Ad Th H. Pruyn, Cees BM Van Riel (2001). "The impact of employee communication and perceived external prestige on organizational identification." Academy of Management journal 44.5 (2001): 1051-1062.

31. Smidts, Ale, Ad Th H. Pruyn, Cees BM Van Riel (2001). "The impact of employee communication and perceived external prestige on organizational identification." Academy of Management journal 44.5 (2001): 1051-1062.

32. Tyler, T. R., Blader, S.L. (2000). Cooperation in groups: Procedural justice, social identity, and behavioral engagement. Psychology Press

33. Vitell, S. J., Saviour, L. Nwachukwu, Barnes, J.H. (1993). "The effects of culture on ethical decision-making: An application of Hofstede's typology.” Journal of Business Ethics 12.10, 753-760.

34. W. De Long, D, Fahey, L. (2000). Diagnosing Cultural Barriers to Knowledge Management. Academy of Management Executive. 14. 113-127.

\section{Article history:}

Received 12 December 2017

Accepted 10 May 2018 